\title{
Feature Extraction for Image Texture Classification
}

\author{
Sidharthraj. R.S, A. John Paul Praveen, S. Balaji
}

\begin{abstract}
Surface request accept a critical activity in PC vision and picture taking care of utilizations. We propose an approach to manage concentrate picture features for surface portrayal. This procedure for removing picture features for request of surfaces is solid to picture insurgency, less sensitive to histogram leveling and bustle. It includes two courses of action of picture features: overpowering close-by twofold models (DLBP) in a surface picture and the beneficial features expelled by using circularly symmetric Gabor channel responses. The predominant close-by twofold model system use the most a great part of the time happened guide to find hypnotizing textural information, while the Gabor-based features go for giving additional overall textural information to the DLBP features.
\end{abstract}

Index terms: Two way relaying, Bidirectional Communications, OFDM, subcarrier pairing, Graphical approach.

\section{INTRODUCTION}

A surface can be uniform, for instance, a square divider, or sporadic, for instance, wood grain or Marble. The fundamental method is to make a $2 \mathrm{D}$ bitmapped image of the surface, called a "surface guide", which is then "collapsed over" the 3D object. A substitute method is to process the surface absolutely through science instead of bitmaps.

The last procedure isn't comprehensively used, anyway can make continuously correct surfaces especially if there is mind blowing significance to the articles being done. An algorithmic strategy for delineating a surface. Not in any manner like a bitmapped surface, in which the surface is addressed as a bitmap, a procedural surface portrays the surface numerically. Regardless of the way that not by and large used, this strategy is objectives independent and can make logically correct surfaces, especially if there is extraordinary and changing significance to the things being done. Procedural surfaces may be 2D or 3D.

\section{DFT TRANSFORMATION}

Despite the fact that the previously mentioned strategies are sealed to be revolution invariant, they are delicate to the difference in brightening condition which regularly exists in surface pictures as a result of the impediment of the imaging gadgets or the difference in lighting condition. In genuine applications, histogram leveling is regularly performed to

Revised Manuscript Received on December 11, 2019

* Correspondence Author

Sidharthraj. R.S, Department of Electronics and Communication Engineering, Bharath Institute of Higher Education and Research, Chennai, Tamilnadu, India. E Mail - sidarthraj93@gmail.com

A. John Paul Praveen, Department of Electronics and Communication Tamilnadu, India. E Mail - johnpaul.embedded@gmail.com

S. Balaji, Department of Electronics and Communication Engineering, Bharath Institute of Higher Education and Research, Chennai, Tamilnadu, India. E Mail - bala.sripathy@gmail.com Engineering, Bharath Institute of Higher Education and Research, Chennai,

alleviate the unfavorable impact of changing enlightenment condition.

Be that as it may, the exhibitions of the above techniques drop altogether after the histogram evening out has been connected on the grounds that, for these strategies, force mean and picture differentiation are two significant bits of textural data for surface grouping. Ojala et al. [19] proposed revolution and histogram adjustment invariant highlights by watching the factual conveyances of the uniform neighborhood double examples (LBPs). Huang et al. broadened the LBP technique by ascertaining the subsidiary based LBPs in the utilization of face arrangement [9]. Be that as it may, the uniform LBPs are not the commanding examples (i.e., examples of the biggest extents in a picture) in certain surfaces with sporadic edges and shapes.

\section{PROPOSED WORK}

The proposed work utilizes another element extraction strategy that is vigorous to histogram evening out and turn. To start with, the ordinary LBP approach is reached out to the predominant nearby twofold example (DLBP) approach so as to successfully catch the overwhelming examples in surface pictures. Dissimilar to the customary LBP approach, which just endeavors the uniform LBP, given a surface picture, the DLBP approach figures the event frequencies of all pivot invariant examples characterized in the LBP gatherings. These examples are then arranged in dropping request. The initial a few most regularly happening examples ought to contain commanding examples in the picture and, in this manner, are the predominant examples. It is demonstrated that the DLBP approach is progressively solid to speak to the ruling example data in the surface pictures.

The proposed methodology has been seriously assessed by applying countless arrangement tests to histogram-evened out, haphazardly pivoted and clamor debased pictures in Outex, Brodatz, Meastex, and CUReT surface picture databases. Our technique has likewise been contrasted and six distributed surface highlights in the investigations.

\section{RESULTS AND DISCUSSION}

Information the preparation picture which will be kept up dedicatedly in the Data base. When the picture is stacked by utilizing the UI, the highlights are extricated by utilizing the gabor channel so as to outline the pixel data for the further union. The prepared picture is then conjured by DLBP calculation to discover the prevailing example of surface happened in the picture through the effective summon of the DLBP (Fig.1), 
the surface data of the picture is separated. Symmetric Gabor Filters: Computing a normal reaction greatness from a Gabor separated picture is a generally utilized component extraction technique. Since Gabor channels can be seen as band pass channels, the normal greatness reaction for every Gabor separated picture can mirror the picture sign intensity of the relating channel passing band. The passing band of a conventional Gabor channel is direction subordinate, which makes it direction delicate and turn variation.

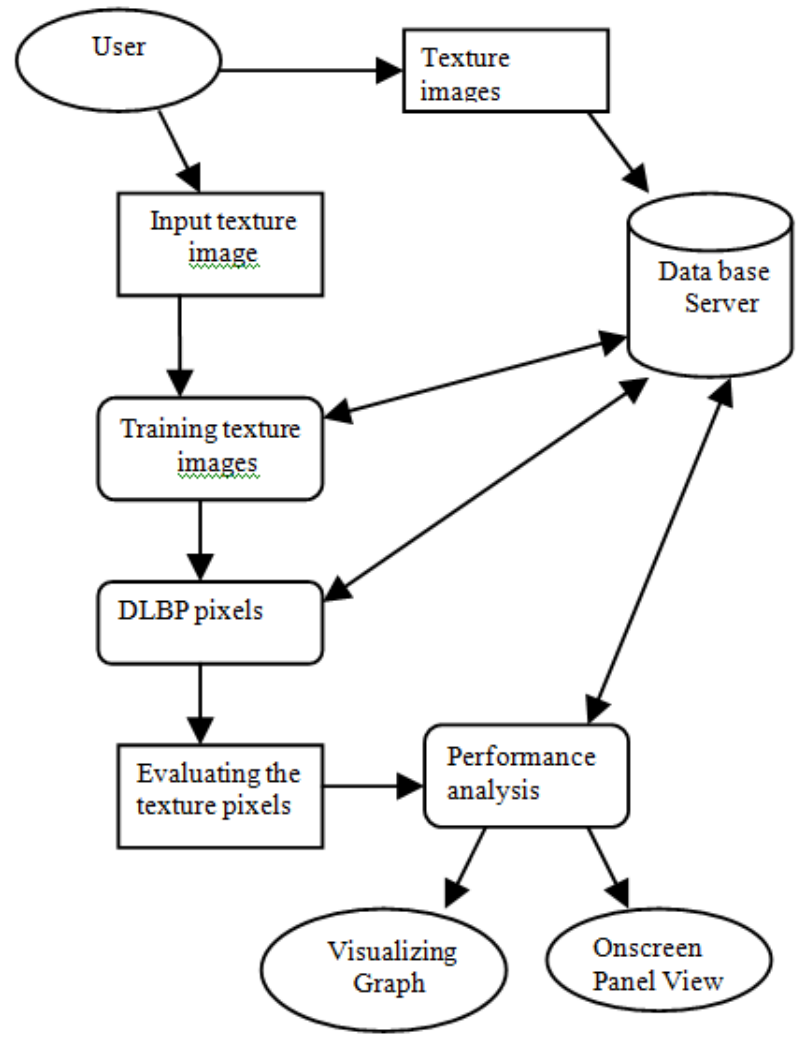

Figure.1 System Architecture

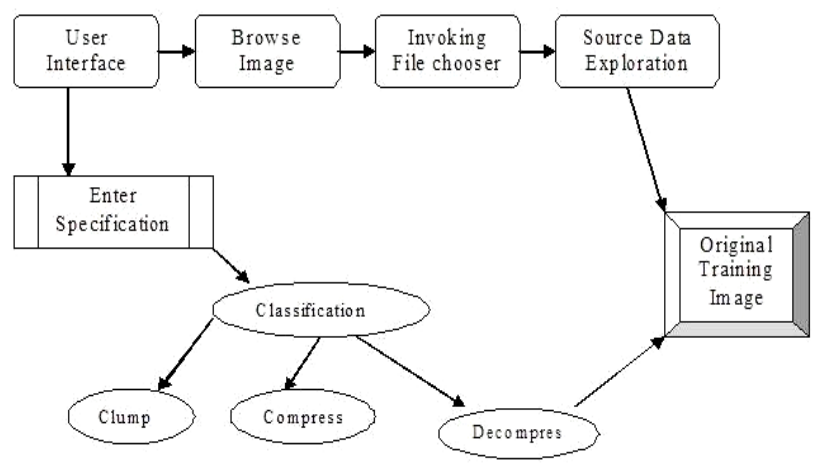

Figure 2 Symmetric Gabor Filter

\section{A.Texture classification through DLBP:}

The Gabor channel reaction sizes are misused to speak to a Gabor sifted surface picture. The normal greatness mirrors the sign quality of a picture in a specific recurrence band. An imperative downside of utilizing the normal sizes is that it is extremely touchy to histogram evening out. This disadvantage clashes invariant to histogram leveling. The picture DC sign is out of the passing groups of all the Gabor channels being utilized. Hence, the standardized normal Gabor channel reaction extents are invariant to the difference in the picture force normal brought about by histogram leveling (see figure 3 ).

In this way, it is appropriate to give worldwide data as an enhancement to the histogram evening out unfeeling DLBP highlights, which does not have the thought of far off pixel associations.

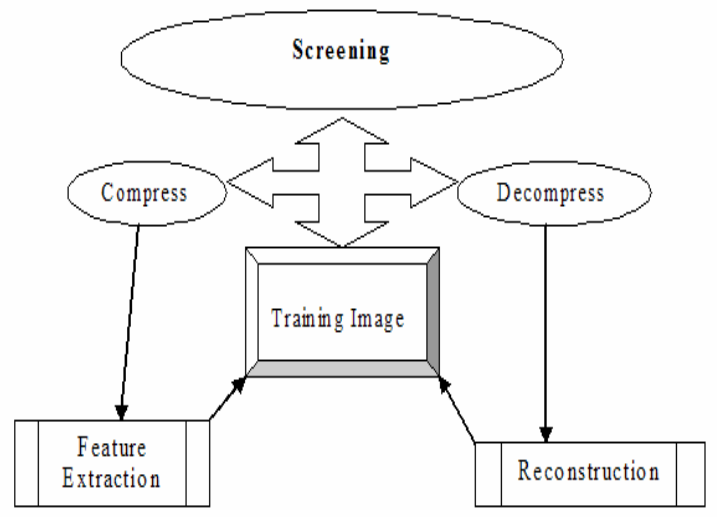

Figure 3 Texture Classification

\section{B.Visualizing texture information:}

Performing surface arrangement under a boisterous domain can inspect the power against clamor in genuine utilizations of various highlights. The normal extent mirrors the sign quality of a picture in a pictures, the required number of examples to possess $80 \%$ example events is resolved before removing the highlights of DLBP. This required number of examples continues as before as the DLBP highlights are in this manner extricated from the preparation picture set or new testing pictures. In any case, for two distinctive surface pictures, the overwhelming examples can be of various sorts. That is, the DLBP approach isn't constrained to consider just a fixed arrangement of examples (e.g., uniform examples).Figure: 4

\section{C.Texture Classification Through DLBP:}

The Gabor channel reaction extents are abused to speak to a Gabor separated surface picture. It is proposed to utilize prevailing neighborhood twofold examples (DLBPs) which consider the most much of the time happened designs in a surface picture. It keeps away from the previously mentioned issues experienced by only utilizing the uniform LBPs or utilizing all the potential examples, as the DLBPs are characterized to be the most much of the time happened designs.

In this undertaking, it will be shown that a base arrangement of example marks that speaks to around $80 \%$ of the all out example events in a picture can adequately catches the picture textural data for characterization errands. Therefore, it is reasonable to give worldwide data as an enhancement to the histogram leveling harsh DLBP highlights, which comes up short on the thought of far off pixel cooperations. 


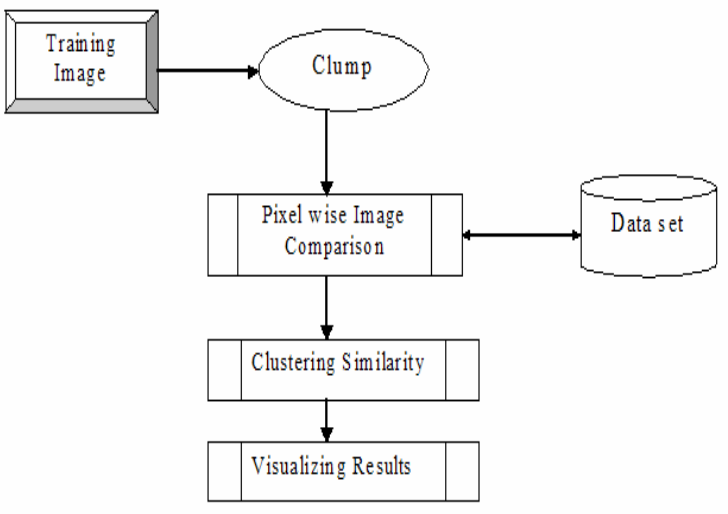

Figure 4 Visualizing The Texture Information

To recover the DLBP highlight vectors from an info picture, the example histogram which considers every one of the examples in the information picture is developed and the histogram containers are arranged in non expanding request. In view of the recently figured number of examples, the event frequencies comparing to the most as often as possible happened designs in the info picture are filled in as the component vectors. It is noticed that the DLBP highlight vectors don't bear data in regards to the overwhelming example types, and they just contain the data about the example event frequencies. As per the trial results, precluding the predominant example type data in the DLBP include vectors isn't unsafe. It is on the grounds that the $80 \%$ overwhelming examples of DLBP is a dominance of the general examples, and the DLBP highlight vectors are now spellbinding.

\section{V.CONCLUSION}

This undertaking proposes the overwhelming nearby double examples (DLBP) as a surface grouping approach. The DLBP approach on one side certifications to have the option to speak to the overwhelming examples in the surface pictures. On the opposite side, it holds the pivot invariant and histogram evening out invariant properties of the customary LBP approach. It is basic and computationally effective. As to choice of the principal $80 \%$ most much of the time seemed designs as highlights after the example recurrence histogram is developed and arranged. It is tentatively demonstrated that it gives great surface arrangement results.

The worldwide highlights extricated by utilizing the circularly symmetric Gabor channel reactions embody the spatial connections between far off pixels. The worldwide highlights extricated from Gabor channel reactions are revolution invariant and less touchy to histogram adjustment. They, in this manner, supplement with the DLBP neighborhood includes as reflected by the trial results. The trial results demonstrate that the proposed technique beats the other picture includes regarding the characterization rates in different picture conditions.

\section{FUTURE WORK}

Starting at now the predominant example of the surfaces for the pictures is yielded. With its proficiency the work can be additionally reached out for the space situated pictures by keeping up the standard data get pre-stacked in the framework. A couple astute coupling characterization approach is taken to empower more prominent explicitness in chose includes and rearrange the element choice procedure. Choosing singular pixel includes as opposed to taking joined spatially touching gatherings of highlights with conceivable excess empowers progressively conservative and engaging models.

\section{REFERENCES}

1. Kumaravel A., Meetei O.N.,An application of non-uniform cellular automata for efficient cryptography,2013 IEEE Conference on Information and Communication Technologies, ICT 2013,V-,I-,PP-1200-1205,Y-2013

2. Kumarave A., Rangarajan K.,Routing alogrithm over semi-regular tessellations,2013 IEEE Conference on Information and Communication Technologies, ICT 2013,V-,I-,PP-1180-1184,Y-2013

3. Dutta P., Kumaravel A.,A novel approach to trust based identification of leaders in social networks,Indian Journal of Science and Technology,V-9,I-10,PP--,Y-2016

4. Kumaravel A., Dutta P.,Application of Pca for context selection for collaborative filtering,Middle - East Journal of Scientific Research,V-20,I-1,PP-88-93,Y-2014

5. Kumaravel A., Rangarajan K.,Constructing an automaton for exploring dynamic labyrinths,2012 International Conference on Radar, Communication and Computing, ICRCC 2012,V-,I-,PP-161-165,Y-2012

6. Kumaravel A.,Comparison of two multi-classification approaches for detecting network attacks, World Applied Sciences Journal,V-27,I-11,PP-1461-1465,Y-2013

7. Tariq J., Kumaravel A.,Construction of cellular automata over hexagonal and triangular tessellations for path planning of multi-robots,2016 IEEE International Conference on Computational Intelligence and Computing Research, ICCIC 2016,V-,I-,PP--,Y-2017

8. Sudha M., Kumaravel A.,Analysis and measurement of wave guides using poisson method,Indonesian Journal of Electrical Engineering and Computer Science,V-8,I-2,PP-546-548,Y-2017

9. Ayyappan G., Nalini C., Kumaravel A., Various approaches of knowledge transfer in academic social network, International Journal of Engineering and Technology,V-,I-,PP-2791-2794,Y-2017

10. Kaliyamurthie, K.P., Sivaraman, K., Ramesh, S. Imposing patient data privacy in wireless medical sensor networks through homomorphic cryptosystems 2016, Journal of Chemical and Pharmaceutical Sciences

11. Kaliyamurthie, K.P., Balasubramanian, P.C. An approach to multi secure to historical malformed documents using integer ripple transfiguration 2016 Journal of Chemical and Pharmaceutical Sciences 9

12. A.Sangeetha,C.Nalini,"Semantic Ranking based on keywords extractions in the web", International Journal of Engineering \& Technology, 7 (2.6) (2018) 290-292

13. S.V.GayathiriDevi,C.Nalini,N.Kumar,"An efficient software verification using multi-layered software verification tool "International Journal of Engineering \& Technology, 7(2.21)2018 454-457

14. C.Nalini,ShwtambariKharabe,"A Comparative Study On Different Techniques Used For Finger - Vein Authentication", International Journal Of Pure And Applied Mathematics, Volume 116 No. 8 2017, 327-333, Issn: 1314-3395

15. M.S. Vivekanandan and Dr. C. Rajabhushanam, "Enabling Privacy Protection and Content Assurance in Geo-Social Networks", International Journal of Innovative Research in Management, Engineering and Technology, Vol 3, Issue 4, pp. 49-55, April 2018.

16. Dr. C. Rajabhushanam, V. Karthik, and G. Vivek, "Elasticity in Cloud Computing", International Journal of Innovative Research in Management, Engineering and Technology, Vol 3, Issue 4, pp. 104-111, April 2018. 
17. K. Rangaswamy and Dr. C. Rajabhushanamc, "CCN-Based Congestion Control Mechanism In Dynamic Networks", International Journal of Innovative Research in Management, Engineering and Technology, Vol 3, Issue 4, pp. 117-119, April 2018.

18. Kavitha, R., Nedunchelian, R., "Domain-specific Search engine optimization using healthcare ontology and a neural network backpropagation approach", 2017, Research Journal of Biotechnology, Special Issue 2:157-166

19. Kavitha, G., Kavitha, R., "An analysis to improve throughput of high-power hubs in mobile ad hoc network" , 2016, Journal of Chemical and Pharmaceutical Sciences, Vol-9, Issue-2: 361-363

20. Kavitha, G., Kavitha, R., "Dipping interference to supplement throughput in MANET" , 2016, Journal of Chemical and Pharmaceutical Sciences, Vol-9, Issue-2: 357-360

21. Michael, G., Chandrasekar, A.,'Leader election based malicious detection and response system in MANET using mechanism design approach", Journal of Chemical and Pharmaceutical Sciences(JCPS) Volume 9 Issue 2, April - June 2016.

22. Michael, G., Chandrasekar, A.,"Modeling of detection of camouflaging worm using epidemic dynamic model and power spectral density", Journal of Chemical and Pharmaceutical Sciences(JCPS) Volume 9 Issue 2, April - June 2016

23. Pothumani, S., Sriram, M., Sridhar, J., Arul Selvan, G., Secure mobile agents communication on intranet,Journal of Chemical and Pharmaceutical Sciences, volume 9, Issue 3, Pg No S32-S35, 2016

24. Pothumani, S., Sriram, M., Sridhar, Various schemes for database encryption-a survey, Journal of Chemical and Pharmaceutical Sciences, volume 9, Issue 3, Pg NoS103-S106, 2016

25. Pothumani, S., Sriram, M., Sridhar, A novel economic framework for cloud and grid computing, Journal of Chemical and Pharmaceutical Sciences, volume 9, Issue 3, Pg No S29-S31, 2016

26. Priya, N., Sridhar, J., Sriram, M. "Ecommerce Transaction Security Challenges and Prevention Methods- New Approach” 2016 ,Journal of Chemical and Pharmaceutical Sciences, JCPS Volume 9 Issue 3.page no:S66-S68

27. Priya, N.,Sridhar,J.,Sriram, M."Vehicular cloud computing security issues and solutions" Journal of Chemical and Pharmaceutical Sciences(JCPS) Volume 9 Issue 2, April - June 2016

28. Priya, N., Sridhar, J., Sriram, M. "Mobile large data storage security in cloud computing environment-a new approach" JCPS Volume 9 Issue 2. April - June 2016

29. Anuradha.C, Khanna.V, "Improving network performance and security in WSN using decentralized hypothesis testing "Journal of Chemical and Pharmaceutical Sciences(JCPS) Volume 9 Issue 2, April - June 2016

\section{AUTHORS PROFILE}

Sidharthraj. R.S Assistant Professor, Department of Electronics and Communication Engineering, Bharath Institute of Higher Education and Research, Chennai, India

A. John Paul Praveen Assistant Professor, Department of Electronics and Communication Engineering, Bharath Institute of Higher Education and Research, Chennai, India.

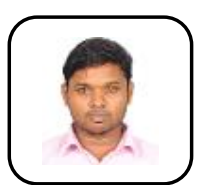

S. Balaji Assistant Professor, Department of Electronic and Communication Engineering, Bharath Institute of Higher Education and Research, Chennai, India. 